\title{
Lavado traqueobrônquico por via nasotraqueal como metodologia de colheita de células do trato respiratório de ovinos sadios e portadores de afecções pulmonares ${ }^{1}$
}

\author{
Julio S. Marcondes², Mayra T.A. Martins², Andreza A. da Silva², Marcela M.P. \\ Rodrigues $^{2}$, Danilo O.L.Ferreira ${ }^{2}$, Renné L. Amorim² ${ }^{2}$ Adriano Dias ${ }^{3}$ \\ e Roberto C. Gonçalves ${ }^{2^{*}}$
}

\begin{abstract}
Marcondes J.S., Martins M.T.A., Silva A.A., Rodrigues M.M.P., Ferreira D.O.L., Amorim R.L., Dias A. \& Gonçalves R.C. 2011. [Tracheobronchial lavage by nasotracheal via to collect cells of respiratory tract of health and broncopneumonic ovines.] Lavado traqueobrônquico por via nasotraqueal como metodologia de colheita de células do trato respiratório de ovinos sadios e portadores de afecções pulmonares. Pesquisa Veterinária Brasileira 31(4):281-286. Departamento de Clínica Veterinária, Faculdade de Medicina Veterinária e Zootecnia, Universidade Estadual Paulista, Distrito de Rubião Junior s/n, Botucatu, SP 18618-000, Brazil. E-mail: calderon@fmvz.unesp.br

Exams of tracheobronchial secretions are widely used in research of lung diseases in several animal species, including men. The objective of this paper was to investigate feasibility of the technique for harvesting trachea-bronchial lavage in sheep and to verify its cliniccytological relationship in healthy sheep and others suffering from pneumonia. In this study 33 sheep were used, 18 healthy and 15 sheep with clinical signs of respiratory disease, divided into groups GS and GD. Clinic examination was performed by obtaining tracheobronchial lavage through the nasal route. The crop was washed with the addition and aspiration of sterile saline. The samples were processed by cytospin and staining with Wright-Giemsa and Shorr. The total cell count and the number of red blood cells per milliliter was higher in the group of sheep with bronchopneumonia. In healthy animals predominance of macrophages was noted, followed by the number of epithelial cells, neutrophils and lymphocytes. In the group of sick animals fewer macrophages and predominance of the neutrophil population were noted. Because of its easy performance to obtain representative material, the technique studied was considered effective to obtain tracheobronchial fluid and therefore is a good method to harvest cells for research of the airways.
\end{abstract}

INDEX TERMS: Respiratory disease, pneumonic, tracheobronchial lavage, cytology, respiratory system, sheep.

RESUMO.- Os estudos das secreções traqueobrônquicas são amplamente utilizados nas pesquisas de doenças pulmonares nas diversas espécies animais, inclusive no homem. Os objetivos desta pesquisa foram a viabilização da

\footnotetext{
${ }^{1}$ Recebido em 28 de agosto de 2010.

Aceito para publicação em 28 de outubro de 2010.

2 Departamento de Clínica Veterinária, Faculdade de Medicina Veterinária e Zootecnia (FMVZ), Universidade Estadual Paulista (Unesp), Campus Botucatu, Distrito de Rubião Junior s/n, Botucatu, SP 18618000, Brasil. *Autor para correspondência: calderon@fmvz.unesp.br

${ }^{3}$ Departamento de Saúde Pública, Faculdade de Medicina de Botucatu (FMB), Unesp, Campus Botucatu, Distrito de Rubião Junior $s / n$, Botucatu, SP.
}

técnica de colheita de lavado traqueobrônquico na espécie ovina e o estudo da relação clínico-citológica do lavado de ovinos portadores de broncopneumonia e sadios. Foram utilizados 33 ovinos, 18 sadios e 15 portadores de enfermidade respiratória com sinais clínicos de envolvimento das vias aéreas, divididos nos respectivos grupos, GS e GD. Após o exame físico foi realizado o lavado traqueobrônquico por via nasotraqueal. A colheita do lavado foi feita com a inoculação e aspiração de solução fisiológica estéril. As amostras foram processadas citologicamente através de citocentrifugação e coradas pelos métodos Wright-Giemsa e Shorr. Tanto a contagem total de células epiteliais quanto o número de hemácias por mililitro foi maior no grupo de 
animais com broncopneumonia. Nos animais sadios notouse predomínio de macrófagos, seguido por células epiteliais cilíndricas, neutrófilos e linfócitos. No grupo de animais doentes havia menor número de macrófagos, e predomínio da população de neutrófilos. Por ser de fácil realização, pouco dispendiosa e pela obtenção representativa de material, a técnica estudada mostrou-se eficaz na obtenção de fluidos traqueobrônquicos e, portanto um bom método de colheita de células para uso nas pesquisas de vias aéreas.

TERMOS DE INDEXAÇÃO: Doenças respiratórias, pneumonia, lavado traqueobrônquico, citologia, aparelho respiratório, ovinos.

\section{INTRODUÇÃO}

A ovinocultura é uma das principais atividades agropastoris no estado de São Paulo. O aumento do número de animais criados associa-se diretamente ao aumento dos problemas respiratórios e perdas econômicas, exigindo desta maneira o desenvolvimento de metodologias para um diagnóstico mais preciso dessas doenças.

Sabe-se da importância do estudo das secreções do trato respiratório em diferentes espécies, como nos eqüinos (Viel 1983) e bovinos (Gonçalves 1997), bem como as técnicas de colheita, já padronizadas e estabelecidas para cada finalidade, tanto para confirmação etiológica (Gonçalves 1987) quanto para a avaliação citológica (Gonçalves 1997, Fernandes et al. 2000). No entanto, a utilização da técnica de colheita do lavado traqueobrônquico em ovinos ainda não é explorada. Como nas outras espécies (Gonçalves 1997, Fernandes et al. 2000, Gonçalves et al. 2004), deve ser útil para o diagnóstico e prognóstico de enfermidades do trato respiratório.

A principal utilização dos ovinos no estudo das secreções broncoalveolares tem como alvo as doenças respiratórias do homem (Górin et al. 1979, Rola-Plesczynski et al. 1981, Bégin et al. 1983, Bossé et al. 1987, Burrells \& Williams 1987, Mornex et al. 1994, Brogden et al. 1998). No entanto, recentemente, Sheehan et al. (2005) demonstraram a utilização do lavado broncoalveolar por via transtraqueal nesta espécie, para no uso diagnóstico de agentes etiológicos e alterações celulares. Trata-se porém de uma técnica invasiva que pode eventualmente ocasionar alterações como hemorragia, celulite e infecção no local de punção da traquéia (Whitwell \& Greet 1984, Hoffman et al. 1997).

O objetivo deste trabalho é descrever uma nova técnica de lavado traqueobrônquico, pela via nasotraqueal, e os achados citológicos em ovinos sadios e naturalmente acometidos por broncopneumonia, com o intuito de aprimorar e aumentar as possibilidades de métodos de colheita de secreções brônquicas na espécie ovina, para uso, tanto no diagnóstico clínico, quanto na pesquisa das enfermidades respiratórias desta espécie.

\section{MATERIAL E MÉTODOS}

Foram incluídos neste estudo 33 ovinos, independentemente de raça e sexo, com idade entre dois e quatro anos, seleciona- dos aleatoriamente em fazendas da região de Botucatu-SP e os encaminhados ao serviço de Clínica de Grandes Animais da Faculdade de Medicina Veterinária e Zootecnia da Unesp de Botucatu.

Os animais foram submetidos ao exame físico do aparelho respiratório para detectar sinais clínicos que caracterizassem afecções respiratórias (Gonçalves 2004). Com base no histórico e na presença de sinais de enfermidade respiratória, foram divididos em dois grupos: Grupo GS constituído por 18 animais sadios, mantidos em sistema semi-intensivo, de acordo com manejo instituído na propriedade; e, Grupo GD constituído por 15 animais, mantidos nas mesmas condições de manejo, no entanto apresentando sinais de broncopneumonia (BCP).

Sondagem nasotraqueal. Para a realização de lavagem traqueobrônquica, os animais foram contidos em estação, com a cabeça e pescoço estendidos e alinhados com a coluna vertebral. Antes da sondagem realizou-se antissepsia da área externa das narinas com álcool iodado a $2 \%$. Em seguida introduziu-se uma sonda guia siliconizada de $70 \mathrm{~cm}$ de comprimento e $5 \mathrm{~mm}$ de diâmetro, previamente esterilizada em óxido de etileno ${ }^{4}$ e embalada individualmente, no vestíbulo nasal, passando pelo meato nasal médio. Quando na orofaringe, foi feito um movimento de rotação de $180^{\circ}$ para direcionar a extremidade da sonda dorsalmente e introduzi-la na laringe e traquéia. Esta sonda foi lubrificada com lidocaína gel para reduzir o desconforto. Meneios de cabeça, saída de ar pela extremidade da sonda guia, seguida ou não de tosse foram os sinais indicativos da localização da sonda na traquéia. A seguir, durante a inspiração, empurrou-se a sonda pela traquéia até a região da carina, quando foi fixada manualmente (Fig.1).

Por dentro da sonda guia foi introduzida uma sonda de polietileno com $85 \mathrm{~cm}$ de comprimento e $3 \mathrm{~mm}$ de diâmetro, adaptada a uma agulha calibre 16, sem bisel, até ultrapassar a extremidade da sonda guia em aproximadamente cinco centímetros, produzindo tosse pelo estímulo direto da carina. A sonda de polietileno era marcada individualmente, para saber o quanto tinha sido introduzida.

Após a sondagem nasotraqueal, as amostras foram colhidas por lavagem traqueobrônquica (Gonçalves et al. 2004, Marcondes 2007). Por meio de uma seringa estéril com capa-

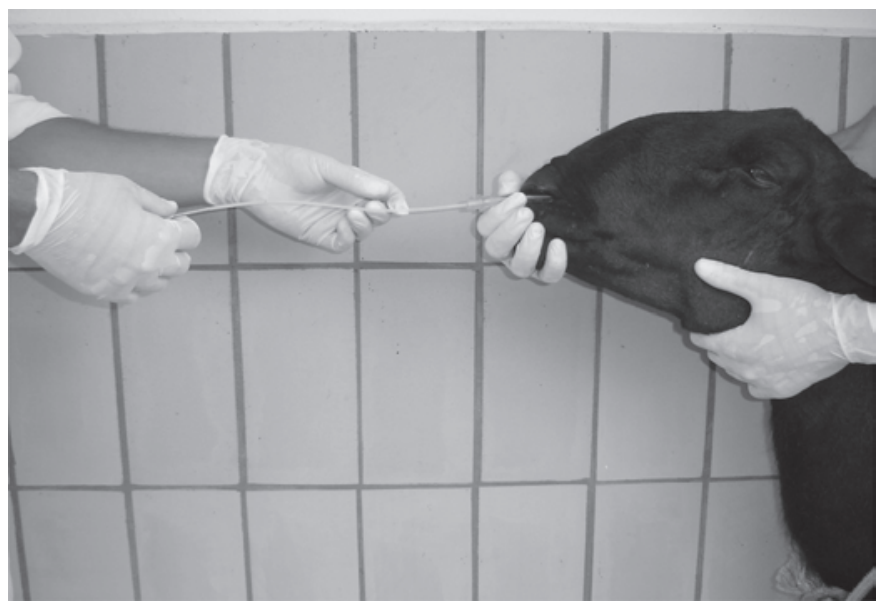

Fig.1. Passagem da sonda de polietileno através da sonda guia siliconizada. Notem-se a fixação da extremidade da sonda guia e contenção da cabeça do animal.

\footnotetext{
${ }^{4}$ Oximed Tecnologia em Esterilização Ltda, São José do Rio Preto, SP.
} 
cidade de $60 \mathrm{ml}$, adaptada ao conjunto sonda de polietilenoagulha foi injetado e imediatamente aspirado um mililitro por quilo de peso vivo de solução salina isotônica comercial estéril e apirogênica. Aspirações sucessivas foram realizadas à medida que a sonda foi progressivamente retirada. Após a obtenção da amostra, o conjunto de sondas foi completamente removido. O líquido aspirado que apresentasse turvação foi considerado adequado para exame citológico.

O lavado traqueobrônquico obtido foi acondicionado em tubo de ensaio de polietileno, armazenado em caixa isotérmica com gelo e enviado ao Laboratório de Citopatologia do Serviço de Patologia da Faculdade de Medicina Veterinária e Zootecnia de Botucatu (FMVZ), Unesp, no tempo máximo de duas horas, para processamento e realização dos estudos citológicos.

Processamento da amostra. Obteve-se a impressão celular de $6 \mathrm{~mm}$ de diâmetro por meio de citocentrifugação ${ }^{5}$ de 200 microlitros do lavado traqueobrônquico a $89 \times$ G por seis minutos, utilizando lâminas histológicas de vidro com extremidade fosca.

Depois de fixadas, as lâminas foram coradas por metodologia de Shorr e Wright-Giemsa. Estas colorações foram utilizadas para identificar as células, avaliar suas características morfológicas e realizar a contagem diferencial.

Contagem total das células. A contagem do número total de células foi realizada em câmara de Neubauer, sem a utilização de corantes. Foram utilizados os nove quadrados da câmara, em analogia com a técnica descrita para contagem de leucócitos (Coles 1984). O número total de células encontrado foi multiplicado por 1,1 (fator de correção), fornecendo o número total de células por microlitro de lavado. Multiplicou-se o valor encontrado por $10^{3}$ para obtenção do valor em células por mililitro (cél/ml).

Contagem diferencial das células. Para cada amostra foram analisados o número e a porcentagem de células epiteliais cilíndricas (CEC), macrófagos (M), neutrófilos (N), linfócitos (L) e eosinófilos (E). Foram contadas 400 células em microscópio óptico comum com aumento de 400 vezes. Nas lâminas que apresentavam muitos aglomerados celulares, a contagem diferencial foi feita na periferia.

Foram anotadas alterações como presença de muco, de partículas estranhas, de neutrófilos degenerados, fagocitose de partículas e/ou de bactérias, eritro e leucofagocitose, vacuolização dos macrófagos, macrófagos bi e tri-nucleados e aglomerados celulares nas amostras.

Análise estatística. Para a análise dos resultados citológicos e de parâmetros vitais, utilizou-se o teste não-paramétrico de Kolmogorov-Smirnov (Zar 2010) com o cálculo da estatística e seus respectivos valores-p. As análises estatísticas foram realizadas no programa SPSS v.15. Nos casos em que $p<0,05$, a diferença foi considerada estatisticamente significativa e foram efetuados testes de contrastes entre as medianas dos grupos de animais sadios e doentes, visto que as variáveis analisadas não tiveram distribuição normal.

\section{RESULTADOS E DISCUSSÃO}

\section{Exame clínico}

Os valores médios encontrados para os parâmetros vitais avaliados nos grupos sadio (GS) e doente (GD), apresentados no Quadro 1, não mostraram diferença estatísti-

\footnotetext{
${ }^{5}$ Revan Centrífuga Ciclo Cito.
}

ca significativa. No entanto, em ambos os grupos, os valores médios para a frequência respiratória foram maiores do que os valores considerados normais por Feitosa (2008).

Os sinais clínicos, com suas respectivas frequências e porcentagens encontradas nos ovinos sadios ( $G S n=18$ )

Quadro 1. Temperatura, frequências respiratória e cardíaca dos ovinos clinicamente sadios e portadores de enfermidade respiratória

\begin{tabular}{cccccc}
\hline Variáveis & Grupos & Média & Mediana & $\begin{array}{c}\text { Desvio } \\
\text { padrão }\end{array}$ & Valor de $p^{*}$ \\
\hline Temperatura & GS $^{\mathrm{a}}$ & 39,01 & 39,00 & 0,55 & 0,606 \\
$\left(^{\circ} \mathrm{C}\right)$ & $\mathrm{GD}^{\mathrm{b}}$ & 38,79 & 38,5 & 0,73 & \\
Frequência & GS & 33,22 & 32,00 & 4,90 & 0,977 \\
Respiratória & GD & 34,80 & 36,00 & 8,27 & \\
Frequência & GS & 88,34 & 88,00 & 10,83 & 0,146 \\
cardíaca & GD & 88,34 & 88,00 & 10,83 &
\end{tabular}

a GS = Grupo de animais sadios, ${ }^{b} \mathrm{GD}=$ Grupo de animais portadores de doença respiratória, " Teste não-paramétrico de Kolmogorov-Smirnov.

Quadro 2. Número e porcentagem dos achados clínicos observados nos ovinos clinicamente sadios e portadores de enfermidades respiratórias

\begin{tabular}{|c|c|c|c|c|}
\hline \multirow[t]{3}{*}{ Sinais clínicos } & \multicolumn{4}{|c|}{ Grupos } \\
\hline & \multicolumn{2}{|c|}{ GS $^{a}(n=18)$} & \multicolumn{2}{|c|}{$G D^{b}(n=15)$} \\
\hline & $\begin{array}{c}№ \text { de } \\
\text { animais }\end{array}$ & $\%$ & $\begin{array}{l}№ \text { de } \\
\text { animais }\end{array}$ & $\%$ \\
\hline Tosse & 0 & 0 & 4 & 26,17 \\
\hline Corrimento nasal & 0 & 0 & 8 & 53,3 \\
\hline Dispnéia mista & 0 & 0 & 1 & 6,7 \\
\hline Frêmito traqueal & 0 & 0 & 0 & 0 \\
\hline Frêmito torácico & 0 & 0 & 0 & 0 \\
\hline Reflexo de tosse & 0 & 0 & 7 & 46,7 \\
\hline Ruído laringo-traqueal aumentado & 0 & 0 & 8 & 53,3 \\
\hline Ruído traqueo-brônquico aumentado & 0 & 0 & 12 & 80,0 \\
\hline Ruído bronco-bronquiolar rude & 0 & 0 & 0 & 0 \\
\hline Área de silêncio & 0 & 0 & 0 & 0 \\
\hline Inspiração entrecortada & 0 & 0 & 5 & 33,3 \\
\hline Crepitação grossa & 0 & 0 & 13 & 86,7 \\
\hline Crepitação fina & 0 & 0 & 0 & 0 \\
\hline Roncos e sibilos & 0 & 0 & 0 & 0 \\
\hline Roce pleural & 0 & 0 & 0 & 0 \\
\hline Odor expiratório pútrido & 0 & 0 & 0 & 0 \\
\hline Temperatura aumentada & 0 & 0 & 1 & 6,7 \\
\hline Frequência respiratória aumentada & 10 & 55,6 & 9 & 60,0 \\
\hline Frequência cardíaca aumentada & 3 & 16,7 & 1 & 6,7 \\
\hline
\end{tabular}

a $\mathrm{GS}=$ Grupo de animais sadios, ${ }^{\mathrm{b}} \mathrm{GD}=$ Grupo de animais portadores de doença respiratória.

Quadro 3. Células nucleadas e hemácias presentes no lavado traqueobrônquico de ovinos clinicamente sadios e portadores de enfermidade respiratória

\begin{tabular}{cccccc}
\hline Variáveis & Grupos & Média & Mediana & $\begin{array}{c}\text { Desvio } \\
\text { padrão }\end{array}$ & $\begin{array}{c}\text { Valor } \\
\text { de } p^{*}\end{array}$ \\
\hline Células Nuclea- & GS $^{\mathrm{a}}$ & $67.661,1$ & $58.125,0$ & $49.297,9$ & 0,168 \\
das(células/ml) & GD $^{\mathrm{b}}$ & $251.563,3$ & 105.600 & $584.581,1$ & \\
Hemácias & GS & $26.027,8$ & $4.675,0$ & $50.218,2$ & 0,713 \\
(células/ml) & GD & $70.390,0$ & $3.300,0$ & $188.736,0$ &
\end{tabular}

a GS = Grupo de animais sadios, ${ }^{b} \mathrm{GD}=$ Grupo de animais portadores de doença respiratória, Teste não-paramétrico de KolmogorovSmirnov. 
e portadores de BCP (GD $n=15)$ estão apresentados no Quadro 3. No grupo sadio foi constatado aumento de frequência respiratória em $55,6 \%$ e aumento da frequência cardíaca em $16,7 \%$ dos animais. Essa elevação foi atribuída ao estresse dos animais durante contenção.

A porcentagem dos sinais clínicos presentes nos animais doentes (Quadro 2), caracterizou o grupo de animais com broncopneumonia (GD). Crepitação grossa e aumento do ruído traqueobrônquico foram os sinais clínicos mais observados, presentes em $86,7 \%$ e $80,0 \%$ respectivamente, seguidos de frequência respiratória aumentada em $60 \%$, de ruído laringotraqueal aumentado e corrimento nasal em $53,3 \%$ e de reflexo de tosse em $46,7 \%$ dos animais. Em proporção intermediária notou-se inspiração entrecortada em $33,3 \%$ e tosse em $26,7 \%$ dos animais do grupo GD. Os sinais menos frequentes foram dispnéia mista e aumento da freqüência cardíaca e da temperatura presentes em 6,7\%.

O grupo de ovinos com broncopneumonia caracterizouse pela maior ocorrência de sinais clínicos que, principalmente em associação, demonstraram comprometimento broncopulmonar (Stöber 1993, Radostits et al. 2002, Gonçalves 2004, Wilson \& Lofstedt 2006). A citologia do LTB dos animais deste grupo mostrou predomínio de neutrófilos seguido por macrófagos, concordando com Gonçalves (1997) que trata da broncopneumonia em bovinos.

Os sinais referentes a frêmito traqueal, frêmito torácico, ruído broncobronquiolar aumentado, área de silêncio, crepitação fina, roncos, sibilos, roce pleural e odor expiratório pútrido, não foram encontrados nos animais do grupo GD. No exame geral do rebanho, verificou-se um número acentuado de animais com corrimento nasal e tosse, embora, sem sinais de envolvimento pulmonar à auscultação e percussão do tórax.

\section{Estudo citológico do lavado traqueobrônquico}

O líquido foi depositado na bifurcação traqueal, evitando-se a limitação provocada pela lavagem broncoalveolar às cegas, realizada com a introdução do tubo guia no brônquio (Taylor et al. 1989, Sweeney \& Beech 1991) ou pela endoscopia (Pringle et al. 1988, Allen et al. 1992). A introdução deste tubo contribuiu, também, para desencadear o reflexo de tosse, favorecendo a colheita de células das regiões mais profundas das vias aéreas (Roszel et al. 1986, Gonçalves 1997).

O Quadro 3 mostra a contagem do número total de células nucleadas e hemácias por mililitro do lavado traqueobrônquico de ovinos clinicamente sadios (GS) e portadores de $\mathrm{BCP}(\mathrm{GD})$. O número médio de células nucleadas encontradas nos grupos GS e GD foram de 67.661,1 $\pm 49.297,9$ e $251.563,3 \pm 584.581,1$ células por mililitro, respectivamente. O grupo sadio apresentou média de hemácias de $26.027,8 \pm 50.218,2$ e o grupo GD de 70.390,0 $\pm 188.736,4$ hemácias por mililitro de lavado. Verificou-se, no grupo GD, aumento tanto do número de células nucleadas quanto do número de hemácias em relação ao grupo GS. Embora não diferindo estatisticamente, este fato mostra que houve descamação celular e afluxo de células decorrentes do processo
Quadro 4. Porcentagem de macrófagos, células epiteliais cilíndricas, neutrófilos, linfócitos e eosinófilos presentes no lavado traqueobrônquico de ovinos clinicamente sadios e portadores de enfermidades respiratórias

\begin{tabular}{ccccc}
\hline Variáveis & Grupos & Média & Mediana* $^{*}$ & $\begin{array}{c}\text { Desvio } \\
\text { padrão }\end{array}$ \\
\hline Macrófagos(\%) & GS $^{\mathrm{a}}$ & 65,69 & $67,87^{\mathrm{c}}$ & 15,84 \\
& GD $^{\mathrm{b}}$ & 38,50 & $26,38^{\mathrm{d}}$ & 25,23 \\
Células epiteliais & GS & 15,35 & $12,66^{\mathrm{C}}$ & 10,04 \\
cilíndricas(\%) & GD & 18,88 & $9,74^{\mathrm{C}}$ & 21,40 \\
Neutrófilos(\%) & GS & 16,67 & $12,13 \mathrm{c}$ & 14,35 \\
& GD & 39,40 & $37,16^{\mathrm{d}}$ & 33,70 \\
Linfócitos(\%) & GS & 1,48 & $1,19^{\mathrm{C}}$ & 1,30 \\
& GD & 1,43 & $0,88^{\mathrm{C}}$ & 1,66 \\
Eosinófilos(\%) & GS & 0,82 & $0,13^{\mathrm{C}}$ & 1,84 \\
& GD & 1,79 & $0,0^{\mathrm{C}}$ & 4,76
\end{tabular}

a $\mathrm{GS}=$ Grupo de animais sadios, ${ }^{\mathrm{b}} \mathrm{GD}=$ Grupo de animais portadores de doença respiratória,

*Medianas seguidas de letras iguais não diferem pelo teste nãoparamétrico de Kolmogorov-Smirnov $(p>0,05)$.

inflamatório (Gonçalves 1997). Apesar disso, a variação do número total de células entre os animais do mesmo grupo foi tão grande, que carece de credibilidade se for utilizado como dado único para interpretação da gravidade do processo inflamatório (Zinkl 2002). A contagem diferencial contorna as dificuldades de se utilizar o número total de células do lavado traqueobrônquico na diferenciação de animais sadios e portadores de afecções respiratórias, mostrando diferença estatisticamente significativa $(p<0,05)$ entre a proporção de células estudadas.

Pelos resultados obtidos neste trabalho (Quadro 4), o lavado traqueobrônquico dos ovinos do GD teve a mesma proporção celular do lavado de bovinos com BCP moderada, segundo Gonçalves et al. (2004), embora não se possa afirmar com segurança a correspondência direta de celularidade entre bovinos e ovinos. Apesar de haver aglomerados de neutrófilos nas lâminas dos animais do GD, seu número era reduzido, o que é citado também por outros autores (Gonçalves et al. 2004).

No GS a porcentagem de macrófagos foi predominante $(65,69 \%)$, seguida por neutrófilos (16,67\%), células epiteliais cilíndricas (15,35\%) e em menores proporções, linfócitos $(1,48 \%)$ e eosinófilos $(0,82 \%)$. No GD a população celular predominante foi de neutrófilos com $39,40 \%$, seguida de macrófagos $(38,50 \%)$, CEC $(18,88 \%)$, eosinófilos $(1,79 \%)$ e linfócitos $(1,43 \%)$.

Comparando-se as medianas dos dois grupos, a menor porcentagem do número de macrófagos do GD $(26,38 \%)$ foi estatisticamente significativa $(p<0,05)$ quando comparada aos $67,87 \%$ do grupo sadio e o aumento na porcentagem de neutrófilos, de $34,26 \%$ no GD, contra os $16,67 \%$ de neutrófilos no grupo GS foi, também, significativa $(p<0,05)$ (Quadro 4).

Essa diferença mostrou-se importante na identificação entre os dois grupos, doentes e sadios, sendo estatisticamente diferentes quando comparadas as medianas dos grupos. Os outros tipos celulares mostraram quantidades pequenas, sem importância para a diferenciação dos grupos sadio e doente. 


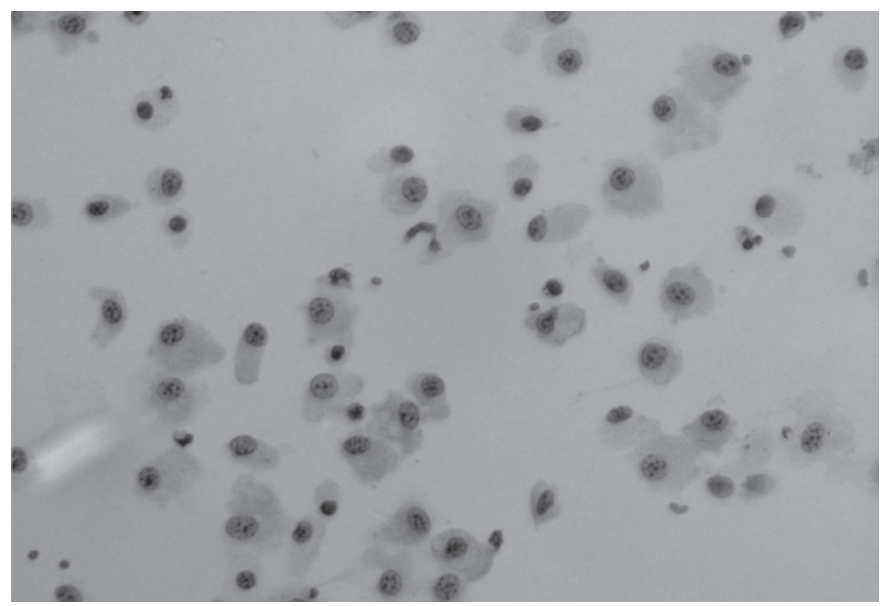

Fig.2. Visão panorâmica de células do lavado traqueobrônquico de ovinos portadores de broncopneumonia, com predomínio de neutrófilos. Giemsa, obj.40x.

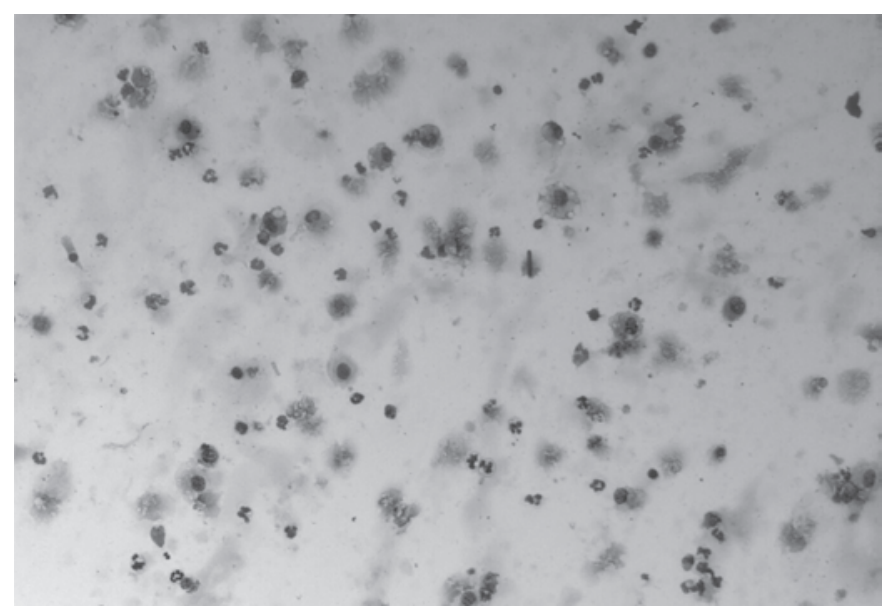

Fig.3. Visão panorâmica de células do lavado traqueobrônquico de ovinos sadios, com predomínio de macrófagos. Shorr, obj.40x.

As porcentagens de linfócitos e eosinófilos, apesar de não diferirem estatisticamente, foram maiores nos animais doentes, com valores de 1,67 e 1,58 do que nos animais sadios, 1,44 e 0,77 respectivamente.

As principais alterações observadas nas lâminas dos animais doentes foram: presença abundante de muco, células epiteliais cilíndricas desprovidas de cílios (ciliocitoftoria), degeneração de neutrófilos, macrófagos binucleados, aglomerados de neutrófilos, presença de bactérias livres e fagocitadas e fagocitose de partículas estranhas (Fig.2). Nos animais do grupo sadio observou-se: macrófagos bi e trinucleados e aglomerados de células cilíndricas ciliadas; em poucos animais deste grupo notou-se presença de muco, bactérias livres e fagocitose de partículas estranhas.(Fig.3)

Principalmente por ser de fácil realização, pouco invasiva, mais acessível economicamente que a endoscopia e de baixo risco quanto às seqüelas nos animais, torna-se uma importante ferramenta na colheita de amostras das vias aéreas inferiores, tanto para pesquisas quanto para o uso pelos profissionais a campo, como auxílio diagnóstico das doen- ças respiratórias. As considerações relacionadas à técnica, bem como a falta de informações nesta espécie, qualificam a lavagem traqueobrônquica por sondagem nasotraqueal com tubo guia, como método opcional excelente para colheita e estudo citológico dos problemas respiratórios nos ovinos.

Agradecimentos.- Ao Dr. Simone Biagio Chiacchio, Departamento de Clínica Veterinária, Faculdade de Medicina Veterinária e Zootecnia da Unesp-Botucatu, pela valiosa ajuda neste trabalho. À Cabanha Guarantã e seus funcionários que disponibilizaram tempo e os animais utilizados neste estudo.

\section{REFERÊNCIAS}

Allen J.W., Viel L., Bateman K.G., Rosendal S. \& Shewen P. 1992. Cytological findings in bronchoalveolar lavage fluid from feedlot calves: Associations with pulmonary microbial flora. Can. J. Vet. Res. 56:122-126.

Bégin R., Rola-Pleszynski M., Massé S., Lemaire I., Siriois P., Boctor M., Nadeau D., Drapeau G. \& Bureau M.A. 1983. Asbestos-induced lung injury in the sheep model: The initial alveolitis. Environmental Research 30:195-210.

Bossé J., Boileau R., Bégin R., Geoffroy M., Martel M. \& Desmarais Y. 1987. Chronic allergic airway disease in sheep model: Functional a lung-lavage features. J. Allergy Clin. Immunol. 79:339-344.

Brogden K.A., Ackermann M. \& Huttner K.M. 1998. Detection of anionic antimicrobial peptides in ovine bronchoalveolar lavage fluid and respiratory epithelium. Infection and Immunity 66:12.

Burrells C. \& Williams J.T. 1987. Bronchoalveolar lavage of the live anaesthetized sheep. Res. Vet. Sci. 42(1):109-112.

Coles E.H. 1984. Patologia Clínica Veterinária. $3^{\underline{a}}$ ed. Manole, São Paulo, p.390-426.

Feitosa F.L. 2008. Semiologia Veterinária: a arte do diagnóstico. $2^{\underline{a}}$ ed. Roca, São Paulo, p.69.

Fernandes W.R., Mori E. \& Sanches A. 2000. Avaliação citológica de lavados traqueobrônquico e broncoalveolar em cavalos clinicamente sadios pelo método de coloração de Rosenfeld. Arq. Bras. Med. Vet. 52:6.

Gonçalves R.C. 1987. Estudo da flora bacteriana traqueobrônquica em bezerros clinicamente sadios e portadores de pneumonia, na região de Botucatu, SP. Dissertação de Mestrado em Patologia Animal, Faculdade de Medicina, Universidade Estadual Paulista, Botucatu, SP. 43p.

Gonçalves R.C. 1997. Estudo clínico e citológico em bezerros clinicamente sadios e portadores de broncopneumonia moderada e grave: 0 lavado traqueobrônquico como complemento diagnóstico. Tese de Doutorado em Clínica de Grandes Animais, Faculdade de Medicina, Universidade Estadual Paulista, Botucatu, SP. 144p.

Gonçalves R.C. 2004. Semiologia do sistema respiratório, p.313-331. In: Feitosa F.L. (Ed.), Semiologia Veterinária. Editora Roca, São Paulo.

Gonçalves R.C., Mattos M.C.F.I., Kuchembuck M.R.G., Lopes R.S. \& Borges A.S. 2004. Lavagem traqueobrônquica por sondagem nasotraqueal em bezerros. Arq. Bras. Med. Vet. Zootec. 56:3307311.

Górin A.B., Stewart P. \& Gould J. 1979. Concentrations of immunoglobulin classes in subcompartiments of the sheep lung. Res. Vet. Sci. 26:126128.

Hoffman A.M. \& Viel L. 1997. Techniques for sampling the respiratory tract of horses. Vet. Clin. North Am., Equine Pract. 13:463-475.

Marcondes J.S. 2007. Estudo clínico-citológico em ovinos sadios e portadores de afecções pulmonares de ocorrência natural, utilizando-se o lavado traqueobrônquico como auxílio diagnóstico. Dissertação de Mestrado em Clínica de Grandes Animais, Faculdade de Medicina Veterinária e Zootécnica, Universidade Estadual Paulista, Botucatu, SP. 123p. 
Mornex J.F., Lena P., Loire R., Cozon G., Greeland T., Guigen F., Jacquier M.F. \& Cordier G. 1994. Lentivirus-induced intersticial disease: Pulmonary pathology in sheep naturally infected by the visnamaedi virus. Vet. Res. 25:478-488.

Pringle J.K., Viel L., Shewen P.E., Willoughby R.A., Martin S.W. \& Valli V.E.O. 1988. Bronchoalveolar lavage of cranial and caudal lung regions in selected normal calves: Cellular, microbiological, immunoglobulin, serological and histological variables. Can. J. Vet. Res. 52:239-248.

Radostits O.M., Gay C.C., Blood D.C. \& Hinchcliff K.W. 2002. Veterinary medicine: A textbook of the diseases of cattle, sheep, pigs, goats and horses. $9^{\text {th }}$ ed. W.B. Saunders, London, p.377-427.

Roszel J.F., Freeman K.P. \& Slusher S.H. 1986. Equine pulmonary cytology. Proc. Annual Convention of the American Association of Equine Practitioners. Am. Assoc. Equine Pract. 31:171-181.

Sheehan M., Markey B., Cassidy J., Ball H.J., Duane M. \& Doherty M.L. 2005. New transtracheal bronchoalveolar lavage technique for the diagnosis of respiratory disease in sheep. Vet. Rec. 157:11:309-313.

Stöber M. 1993. Aparelho respiratório, p.139-165. In: Dirksen G., Gründer. H.D. \& Stöber M. (Eds), Exame Clínico dos Bovinos. $3^{\text {a }}$ ed Editora Guanabara Koogan, Rio de Janeiro.
Sweeney C.R. \& Beech J. 1991. Bronchoalveolar lavage, p.55-61. In: Beech J. (Ed.), Equine Respiratory Disorders. Lea and Febiger, Pennsylvania.

Taylor G., Thomas L.H. \& Stott E.J. 1989. Effect of vaccination on cell populations in lung washes from calves after infection with respiratory syncytial virus. Res. Vet. Sci., 47:231-235.

Viel L. 1983. Structural functional correlations of the lung in horses with small airway disease. PhD Dissertation, University of Guelph, Ontario, Canada.

Whitwell K.E. \& Greet T.R.C. 1984. Collection and evolution of traqueobronchial washes in the horse. Equine Vet. J. 16:6:499508.

Wilson W.D. \& Lofstedt J. 2006. Alterações na função respiratória, p.314. In: Smith B. (Ed.), Medicina Interna de Grandes Animais. 3aㅡ ed. Manole, Barueri, SP.

Zar J.H. 2010. Bioestatistical Analysis. $5^{\text {th }}$ ed. Prentice-Hall, New Jersey, p.736-746.

Zinkl J.G. 2002. Lower respiratory tract, p.73-86. In. Cowell R.L. \& Tyler R.D. (Eds), Diagnostic Cytology and Hematology of the Horse. $2^{\text {nd }}$ ed. Mosby, Missouri. 